\title{
Continuance Intention to Third-Party Mobile Payment Usage: An Extended Theory of Planned Behavior Perspective
}

\author{
Wenchuan Zhu \\ School of Management, University of Science and Technology of China, Hefei, China \\ Email address: \\ chuanshuanghu@163.com \\ To cite this article: \\ Wenchuan Zhu. Continuance Intention to Third-Party Mobile Payment Usage: An Extended Theory of Planned Behavior Perspective. \\ International Journal of Law and Society. Vol. 2, No. 2, 2019, pp. 22-25. doi: 10.11648/j.ijls.20190202.12
}

Received: May 26, 2019; Accepted: June 27, 2019; Published: August 6, 2019

\begin{abstract}
At present, China has become the world's largest mobile payment market, and the mobile payment has penetrated into every aspect of people's lives. Mobile payment is a service that allows users to use their mobile terminals (usually mobile phones) to pay for goods or services they consume. The mobile payment giant represented by Alipay and WeChat has launched fierce commercial competition in this industry. Analysis and discussions of end users' continued use intention of mobile payment are of great importance for mobile payment companies to maintain existing markets and expand into new markets. Therefore, this study adopted an extended planned behavior theory to explore the influence of perceived convenience, risk perception and attitude of users on the behavioral intention of continuous use. This paper collected the data of 300 Alipay and WeChat users in China through questionnaire survey. Structural equation model was used to verify the proposed hypotheses. The results indicated that perceived convenience has positive effects on users' attitude and their continued use intention. Risk perception has negative impacts on users' attitude and the intention of continuous use. Furthermore, users' attitude has a positive effect on the continued use intention. Finally, based on the analysis results, this paper discussed some policy implications on how to improve users' continuous use behavior.
\end{abstract}

Keywords: Mobile Payment, Continuous Use, Risk Perception, Perceived Convenience

\section{Introduction}

In recent years, with the rapid increase of mobile Internet users and the wide spread popularity of smart phones, the scale of third-party mobile payment has shown explosive growth in China. Mobile payment is a service that allows users to use their mobile terminals (usually mobile phones) to pay for goods or services they consume. At present, mobile payment has penetrated into every aspect of consumers' life and the frequency of use of cash in daily life is getting lower and lower. Furthermore, mobile payment is regarded as one of the four major inventions of China in the new era, becoming a new business card for China to go global. In 2017, the size of China's mobile payment market exceeded 100 trillion yuan, which is more than four times that of the 29 trillion PC payment businesses. In addition, data from the quarterly monitoring report of China's third-party payment mobile payment market released by Analysys showed that the transaction scale of China's third-party payment mobile payment market reached $4,0364.51$ billion yuan in the first quarter of 2018, with a month-on-month growth of $6.99 \%$. In short, going "cashless" has become an inevitable trend in the future.

The huge mobile payment market has spawned two giants in the mobile payment industry, namely WeChat Payment and Alipay. In the first quarter of 2018, Alipay's market share was $53.76 \%$, WeChat was $38.95 \%$, and One Wallet was $1.33 \%$. Alipay and WeChat accounted for $92.71 \%$ of the current market share, which were in an absolute leading position. In order to consolidate their respective market positions, companies have adopted a series of measures to launch fierce competition. For example, WeChat Pay took advantage of WeChat's portal traffic, expanded the overall commercial payment scenario, and launched activities such as shaking red envelopes to drive offline transactions. On the other hand, Alipay has increased the investment in offline code scanning and carried out person-to-person red envelope activities to drive its commercial payment scale. No matter what measures mobile payment companies take, their goal is to enhance the sense of experience and loyalty of end users. Therefore, 
strengthening users' intention of continuous use is of fundamental importance for companies to consolidate and expand their existing market share.

This paper proposed an extended theory of planned behavior to understand the psychological factors and influence paths that affect the user's continued use intention of mobile payment. The theory of planned behavior was proposed by Azjen in 1985 to predict consumers' behaviors, including three key variables: attitudes, subjective norms, and perceived behavioral control [1]. At present, the penetration rate of smartphones has reached a very high level in China. According to the statistics of the well-known Pew Research Center in the United States, the smartphone user rate in China has reached $68 \%$ in 2018 . Also, all mobile payment app downloads are free and fully compatible with all models of mobile phone systems. Therefore, subjective norms and perceived behavioral control has weaker impacts on the use of mobile payment systems. Instead, users' attitudes toward mobile payment apps will play an important role, directly affecting their continued use behavior. According to Kim et al. [2], users' attitudes play a key mediating role in many factors that affect the use of mobile payment services.

\section{Theoretical Framework and Hypotheses Development}

There are two main reasons for the rapid rise of mobile payments in China. First, China's financial system is not perfect. Compared with Europe and the United States, the credit payment system is not perfect between different regions and cities in China. In many payment scenarios, full credit card payment cannot be made. This provides an opportunity for the rapid rise of mobile payment services represented by Alipay and WeChat payment. Second, mobile payments bring great convenience to users. Cashless and fast payment has eliminated the need for users to carry a lot of cash and change the transaction process. In fact, in order to improve the user's experience, mobile payment companies not only strive at the technical level, but also strive to improve the convenience of user use in function settings. Sorce et al. [3] analyzed the psychological factors of users' online shopping behavior and pointed out that perceived convenience has a significant influence on users' online shopping attitudes and continuous shopping behavior. Ozturk et al. [4] pointed out that the perceived convenience of users has a positive impact on the loyalty of customers in booking hotels through mobile phones. Therefore, this study chooses the perceived convenience of users as an important antecedent.

Additionally, in the field of social psychology research, the risk perception as an important psychological factor has attracted wide attentions. Many scholars have defined it from different angles. The more accepted definition for scholars is: risk perception refers to the potential negative utility of a user's purchase behavior to purchase a product or a service [5]. The degree of risk perception of users has an important impact on their decision-making process [6]. Previous studies have shown that the level of risk perception has a considerable negative impact on the user's attitudes and eventual adoption of an innovative product or service. In this research context, as an innovative payment service product, mobile payment service is obviously influenced by risk perception.

Based on the above discussion, this study proposed the following theoretical framework (Figure 1). Six hypotheses are listed as follows, namely:

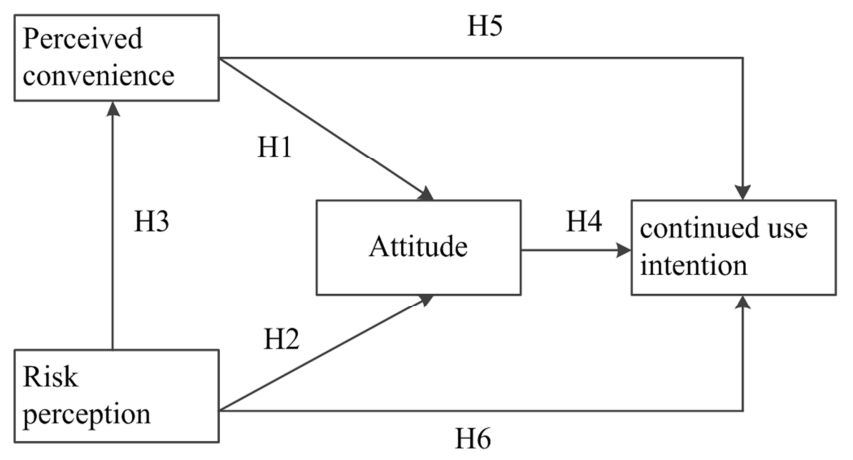

Figure 1. The theoretical framework of this research.

Hypothesis 1: Perceived convenience positively impacts on users' attitudes toward using mobile payment services.

Hypothesis 2: Risk perception negatively impacts on users' attitudes toward using mobile payment services.

Hypothesis 3: Risk perception negatively impacts on users' perceived convenience to use mobile payment services.

Hypothesis 4: Users' attitudes toward using mobile payment services positively impact their continued use intention.

Hypothesis 5: Perceived convenience positively impacts on users' continued use intention to use mobile payment services.

Hypothesis 6: Risk perception negatively impacts on users' continued use intention to use mobile payment services.

\section{Research Method}

\subsection{Measurement Scale and Data Collection}

The items of the constructs in this paper were developed from previous research. Some of the wordings of the item-scale were slightly modified to fit the research context. 3 items measuring perceived convenience were adapted from the studies of Chang et al. [7]. To measure risk perception, 4-item scales were adapted from Thakur and Srivastava [8]. Attitudes toward using mobile payment services were measured by 3 items modified from Arvidsson [9]. 3 items adapted from Jia et al.[10] were used to measure continued use intention of users. All the items were measured on a 7-point scale from 1 for "strongly disagree" to 7 for "strongly agree". The questionnaire survey was conducted to collect the data. The respondents were EMBA, MBA and some master and doctoral students of University of Science and Technology of China (USTC). The respondents should have the economic foundation and the experiences of using mobile payment.

The collection period ranged from December 2018 to February 2019. The process of the survey divided into two steps. The first step is pre-survey and sample screening. The investigators communicated with the users of the mobile payment app included in the survey sample and informed 
them the purpose of this survey to ask if the respondents are willing to participate in this survey. Finally, 400 users were contacted. Among them, 340 users agreed to participate in the survey, the response rate is $85 \%$. Then, the investigators used the Questionnaire Star, a professional questionnaire distribution platform to send the electronic questionnaire to 340 respondents. In order to improve the enthusiasm of the respondents to participate in the survey, when the respondents complete the questionnaire, they will receive cash ranging from 5-10 yuan as a reward. Totally, 300 valid questionnaires were collected with the response rate of $75 \%$.

\subsection{Sample Profile}

Respondents' demographic profiles are shown in Table 1. As presented in Table 1, male and female respondents account for $46.67 \%$ and $53.33 \%$, respectively. In terms of age distribution, the proportion less than 25 years old is $5 \%$, and the group between 25 and 30 years old is the largest, accounting for $40 \%$; the percentage of the group between 31 and 45 years old is $36.67 \%$, and the percentage of the group between 46 and 60 years old is $16.67 \%$. As the respondents of this survey are students from USTC, their level of education is high, among which $20 \%$ have bachelor's degree and $80 \%$ have master's degree or above. Finally, from the perspective of income distribution, $21.67 \%$ of users' income is less than 5,000 yuan, $43.33 \%$ of users' income is between $5000-15000$ yuan, and $26.67 \%$ of users' income is between 15001-30000 yuan, $8.33 \%$ of which is higher than 30,000 yuan.

Table 1. Respondents' demographic information.

\begin{tabular}{llll}
\hline \multicolumn{2}{l}{ Demographic characteristic } & Number & Percentage \\
\hline \multirow{2}{*}{ Gender } & Male & 140 & $46.67 \%$ \\
& Female & 160 & $53.33 \%$ \\
& Lower than 25 & 15 & $5.00 \%$ \\
Age & $25-30$ & 120 & $40.00 \%$ \\
& $31-45$ & 110 & $36.67 \%$ \\
\multirow{3}{*}{ Educational } & Larger than 60 & 50 & $16.67 \%$ \\
level & Master's or higher degree & 5 & $1.66 \%$ \\
Monthly & Less than 5,000 & 60 & $20.00 \%$ \\
household & 5,000-15,000 & 65 & $80.00 \%$ \\
income (¥) & 15,001-30,000 & 130 & $21.67 \%$ \\
& More than 30,000 & 80 & $43.33 \%$ \\
\hline
\end{tabular}

\section{Data Analysis and Results}

Amos 21.0 was used in this section to conduct path analysis to verify the theoretical framework and measure the path coefficients in the model. The measurement results of structural equation model are shown in Table 2. The results in Table 2 indicated that T-values of perceived convenience, risk perception, attitudes, and the continued use intention were all meet the significance criteria. Furthermore, the results of analysis showed that the chi-square ratio was $4.328(\mathrm{p}<0.05)$, and other indicators (TLI $=0.808, \mathrm{CFI}=0.783$ ) were also acceptable, indicating that the theoretical framework fits the collected data well $[11,12]$.
Table 2. Results of structural equation model.

\begin{tabular}{lllll}
\hline Relationships & Pc & T-value & Hypotheses & Judgment \\
\hline PC->AT & 0.203 & $4.133 * * *$ & H1 & supported \\
RP->AT & -0.412 & $6.852 * *$ & H2 & supported \\
RP->PC & -0.104 & $4.502 *$ & H3 & supported \\
AT->CUI & 0.355 & $8.542 * * *$ & H4 & supported \\
PC->CUI & 0.433 & $7.265 * *$ & H5 & supported \\
RP->CUI & -0.246 & $5.263 *$ & H6 & supported \\
\hline
\end{tabular}

Note: (1) Pc: path coefficients;

(2) $* \mathrm{p}<0.05, * * \mathrm{p}<0.01$, and $* * * \mathrm{p}<0.001$.

Figure 2 presented the results of the path coefficients. Perceived convenience has a significant and positive impact on users' attitudes towards mobile payment services $(\mathrm{Pc}=0.203, \mathrm{~T}=4.133, \mathrm{p}<0.001)$, showing $\mathrm{H} 1$ is supported. Risk perception has a significant negative impact on users' attitudes towards mobile payment services $(\mathrm{Pc}=-0.412, \mathrm{~T}=6.852$, $\mathrm{p}<0.01$ ), indicating $\mathrm{H} 2$ is supported. The risk perception has a significant negative impact on the perceived convenience of users' mobile payment $(\mathrm{Pc}=-0.104, \mathrm{~T}=4.502, \mathrm{p}<0.05)$, presenting $\mathrm{H} 3$ is supported. The attitudes toward the mobile payment services have a significantly positive impact on the user's continued use intention $(\mathrm{Pc}=0.355, \mathrm{~T}=8.542, \mathrm{p}<0.01)$, assuming $\mathrm{H} 4$ is verified. The perceived convenience of users has a positive effect on the continued use intention $(\mathrm{Pc}=0.433$, $\mathrm{T}=7.265, \mathrm{p}<0.01$ ), assuming $\mathrm{H} 5$ is supported. The risk perception has a negative impact on the continued use intention $(\mathrm{Pc}=-0.246, \mathrm{~T}=5.263, \mathrm{p}<0.05)$, assuming $\mathrm{H} 6$ is supported.

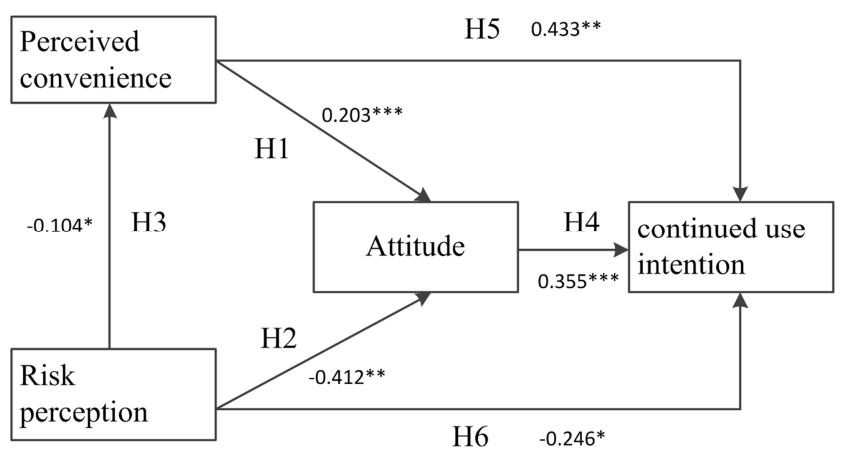

Figure 2. The results of hypotheses.

\section{Discussion}

Based on data analysis, it is found that the level of user's risk perception has a significant negative on several other variables (such as risk perception, perceived convenience, et al.). Actually, these results is consistent with our daily life intuitive observation. According to the theory of loss aversion $[12,13]$ and risk aversion [14-15], people would generate psychological aversion and try to avoid risk when they face potential risks [16]. As for mobile payment tools, the security of the payment is one of the core of consumers' consideration. When users are faced with mobile payment services, which provided by different companies, the behavior decision of the payment tool selection is risk avoidance. Thus, for mobile payment companies, this poses a technical challenge. And, 
each payment company should strive to improve its security trading technology and enhance the users to experience safe use. Furthermore, the user's perceived convenience is also the core consideration for user to choose payment tools. Timeliness of payment, the support of merchant's mobile payment type and other factors will significantly affect the attractiveness of mobile payment to users.

\section{Conclusions}

Mobile payment has penetrated into every aspect of people's lives. From the payments for daily diet and travel to the payments for large items such as home appliances and automobiles, mobile payment services are frequently used. China's huge population base and market size have determined that China has a huge market space in the field of mobile payments. In the increasingly competitive market environment, exploring the continued use intention of users to use mobile payment plays an important role in the expansion of existing market share for companies. Based on the theory of planned behavior, this study added perceived convenience and risk perception to propose an extended theory of planned behavior model, which attempted to explore the continued use intention of users. The questionnaire survey was conducted to collect the data. SPSS and AMOS statistical analysis software were used to verify the hypotheses. There are several implications.

According to the results of this research, companies can improve users' continued use intention to use the mobile payment services and enhance their stickiness, which can be improved from the following aspects. First, companies should design more user-friendly services and optimize the operation process, so that users can feel more convenient to use the mobile payment services. Second, companies should improve the level of security prevention. This can not only ensure the safety of users when paying funds, but also create a high level of high-quality protection of users' privacy. Thirdly, actively publicize various functions of mobile payment should also be activated to improve users' cognitions of mobile payment services.

\section{References}

[1] Hale, D., Khan, S., Thakur, R., \& Angriawan, A. (2017). Gifted Innovation: An Examination Using Different Business Theories. The Journal of Business Inquiry, 17 (1), 4-22.

[2] Kim, C., Mirusmonov, M., \& Lee, I. (2010). An empirical examination of factors influencing the intention to use mobile payment. Computers in Human Behavior, 26 (3), 310-322.

[3] Sorce, P., Perotti, V., \& Widrick, S. (2005). Attitude and age differences in online buying. International Journal of Retail \& Distribution Management, 33 (2), 122-132.

[4] Ozturk, A. B., Bilgihan, A., Nusair, K., \& Okumus, F. (2016). What keeps the mobile hotel booking users loyal? Investigating the roles of self-efficacy, compatibility, perceived ease of use, and perceived convenience. International Journal of Information Management, 36 (6), 1350-1359.

[5] Schaefers, T., Lawson, S. J., \& Kukar-Kinney, M. (2016). How the burdens of ownership promote consumer usage of access-based services. Marketing Letters, 27 (3), 569-577.

[6] Chen, R., \& He, F. (2003). Examination of brand knowledge, perceived risk and consumers' intention to adopt an online retailer. Total Quality Management \& Business Excellence, 14 (6), 677-693.

[7] Chang, C. C., Yan, C. F., \& Tseng, J. S. (2012). Perceived convenience in an extended technology acceptance model: Mobile technology and English learning for college students. Australasian Journal of Educational Technology, 28 (5).

[8] Thakur, R., \& Srivastava, M. (2014). Adoption readiness, personal innovativeness, perceived risk and usage intention across customer groups for mobile payment services in India. Internet Research, 24 (3), 369-392.

[9] Arvidsson, N. (2014). Consumer attitudes on mobile payment services-results from a proof of concept test. International Journal of Bank Marketing, 32 (2), 150-170.

[10] Jia, L., Hall, D., \& Sun, S. (2014). The effect of technology usage habits on consumers' intention to continue use mobile payments.

[11] Martin, S. L., \& Javalgi, R. R. G. (2016). Entrepreneurial orientation, marketing capabilities and performance: the moderating role of competitive intensity on Latin American International new ventures. Journal of Business Research, 69 (6), 2040-2051.

[12] Garbarino, E., Slonim, R., \& Villeval, M. C. (2019). Loss aversion and lying behavior. Journal of Economic Behavior \& Organization, 158, 379-393.

[13] Kuo, N. T., Cheng, Y. S., Chang, K. C., \& Chuang, L. Y. (2018). The asymmetric effect of tour guide service quality on tourist satisfaction. Journal of Quality Assurance in Hospitality \& Tourism, 19 (4), 521-542.

[14] Guiso, L., Sapienza, P., \& Zingales, L. (2018). Time varying risk aversion. Journal of Financial Economics, 128 (3), 403-421.

[15] Cohn, A., Engelmann, J., Fehr, E., \& Maréchal, M. A. (2015). Evidence for countercyclical risk aversion: An experiment with financial professionals. American Economic Review, 105 (2), 860-85.

[16] O' Donoghue, T., \& Somerville, J. (2018). Modeling risk aversion in economics. Journal of Economic Perspectives, 32 (2), 91-114. 